\title{
From science to policy
}

\author{
As the 26th UN Climate Change Conference of the Parties (COP26) in Glasgow nears, calls for politicians to heed \\ the warnings on climate change increase. We talked to Atte Harjanne, a member of parliament in Finland, to hear \\ how some politicians are trying to incorporate scientific findings in their decisions.
}

Can you please tell us about your position in the Finnish government and how you or your office is involved in decision-making on climate change? I'm a member of parliament representing the Green Party, which is part of the current government coalition led by the Social Democrats. I have a seat in the Commerce Committee, which is the parliamentary body largely responsible for energy and finance sector legislation. The committee prepares parliament's response to legislative proposals and government reports in these sectors and comments on other climate-related acts and strategies as well. Energy and finance are naturally key sectors in climate change mitigation as we need to decarbonize energy production and guide financial markets to invest in a sustainable transition. This has also expanded the committee's perspective from a traditional macroeconomics point-of-view to include climate change mitigation as well.

\section{What is your exposure to science on climate change? What type of publica- tions or evidence comes to your desk through formal processes and where do you obtain knowledge on climate change informally?}

Formally the most important exposure comes from expert hearings in the parliament. The most important institution here is the Finnish Climate Change Panel, the official national scientific advisory body on climate science, but individual researchers and research institutions are important as well. IPCC is naturally a key institution as well, especially now as the Sixth Assessment Report (AR6) publications start. I personally have a professional background in climate change research, so I perhaps know a little better where to look and I try to frequently browse through recent research publications. Summarizing popularizations - like the Nature Podcast are a pretty good way to stay informed.

Do you think science is adequately being considered in decision-making in Finland?

Yes and no. We have an ambitious, science-based goal of being carbon neutral by 2035 and carbon negative afterwards and

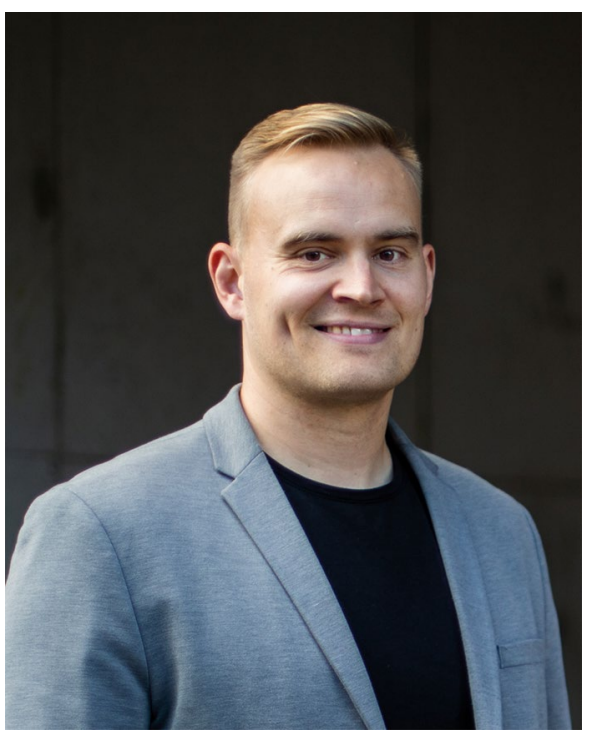

is what politicians talk about and are asked to comment on. So, it is important that research and findings are communicated effectively to journalists. Here, educating journalists can be helpful. Being active in social media can also be an effective way to convey findings as an individual researcher, but here I expect researchers to be responsible. It is also desirable to comment on and popularize research more broadly than just one's own contributions, but it's important to make sure the context and overall picture are communicated alongside single interesting results. The problem is that we politicians tend to be prone to cherry-picking research headlines that fit our agendas best.

In general, infographics, illustrations and compact messages reach politicians better.

\section{What are the key gaps or areas of research that you feel scientists should focus on? What questions do you want answered? \\ First of all, I would like to emphasize that}

climate policy has become a mainstream issue across policies ranging from energy and transportation to agriculture and security. Yet we don't really walk the talk yet, and in many sectors the actions remain inadequate. Agriculture, peat use and forestry are perhaps the most challenging and are kind of national blind spots. Although we have some good practices and policies in place, there's still a lot to do to reduce emissions and strengthen carbon sinks and storages. These are either economically or socially important sectors, where accumulating scientific knowledge challenges traditional views and short-term economic interests. This led some policymakers and lobby organizations to even try to dispute or undermine academic research. Examples of this are efforts to classify peat as a renewable resource by including peat extraction and burning as natural carbon sinks in the emission balance, or by downplaying human impact on climate.

What key recommendations would you have for the scientific community to more effectively communicate their findings to you and your colleagues?

It is important to understand the role of the media here - very few politicians really read scientific texts and what is in the news lack of scientific information is not the main bottleneck for action now: lack of political will and capacity is. This doesn't mean that new research isn't valuable: it is, and it is critically needed too.

From my point of view, key information is needed in the area of rapid scaling of decarbonization. How to mobilize economies and economic sectors to undertake the challenge of getting rid of fossil fuel dependency and building decarbonized energy systems in the speed required? This is a massive engineering challenge too. In general, I want to emphasize that scale is important in contextualizing scientific information. All climate actions should also be considered in a global context. Can they be scaled and how?

I'm also worried that some taboos limit the science-policy interaction and even the research itself. Nuclear energy is an example of this: it's a tried-and-true way to produce low-carbon energy relatively quickly, yet it is often ignored in energy models or limited with quite confined background assumptions. Geoengineering is another. This planet, it's climate and biosphere are already modified by us quite thoroughly — that's why we are in 
this mess - and our 1.5-degree pathways rely on massive-scale carbon removal anyway. Emission reductions are a clear and overwhelming priority, but it's better to study all the possibilities early on in case we need them.

What do you think governments and the government in Finland in particular can do better to engage with the scientific community and to have more evidence-backed decision-making? It's important that governments act as champions for science-based policies in general and accept scientific information as the basis that sets the boundaries for policy-making. As Finnish researcher Janne M. Korhonen once said, politicians can make the physically possible impossible, but they cannot make the physically impossible possible. In the face of climate change the idea of a business-as-usual development being an option should be scrapped.
Finland has for instance stated in its EU strategy that we promote science-based decision-making to tackle climate change and loss of biodiversity. On that claim, we have yet to put our money and effort where our mouth is, but it's a start. Science-based decision-making also requires a very difficult thing from politicians: the ability to change one's mind as new information becomes available.

Independent scientific advisory bodies are an important institutional way to engage the scientific community. More of these should be established. Politics is of course value-based decision-making in its core, and it shouldn't be outsourced to scientists, but it should be done based on the best available scientific knowledge.

\section{What would be your optimistic outlook on outcomes from COP26?}

It'd be great to see enhanced ambition on emission cuts backed with actual plans on how those are done. I hope the publication of the first AR6 contribution increases political pressure on governments around the world prior to COP26.

The economic and societal impacts of COVID-19 have been very unequally distributed, and this emphasizes the need for global climate solidarity and justice even more than before. The wealthy nations need to acknowledge the situation and make sure the developing nations have the institutions, funding and technology available to ensure their development is possible but not fossil energy fuelled. With great power comes great responsibility, as the Spider-Man principle goes. The wealthy nations need to take their responsibility seriously.

Interviewed by Fouad Khan

Published online: 11 October 2021

https://doi.org/10.1038/s41560-021-00916-4 